\title{
Challenges To Attenuate Ureteric Stent-Related Symptoms: Reflections On The Need To Fashion A New Dynamic Stent Design Consequent Upon A Case Report
}

This article was published in the following Dove Press journal:

Research and Reports in Urology

\section{Benoît Vogt (D)}

Department of Urology, Polyclinique de Blois, La Chaussée Saint-Victor 4I260, France
Correspondence: Benoît Vogt Department of Urology, Polyclinique de Blois, I rue Robert Debré, La Chaussée Saint-Victor 41260, France

Tel +332549065 I I

Fax +33254906566

Email message@benoitvogt.fSr

\begin{abstract}
Double-pigtail stent has been widely used in urology for half a century now, but this device reduces the patient's quality of life. Moreover, indwelling stent-related symptoms induce additional suffering to the pre-existing bladder disease. Novel concepts to prevent stent-related symptoms are greatly required. It has been suggested that changes in the size, form and stent positioning could ease discomfort. By decreasing the amount of material within the bladder, it should be possible to attenuate the stent-related symptoms. A customized stent has been developed to alleviate bladder symptoms. The major characteristic of this stent was in the replacement of the bladder part of the double-pigtail stent by a nonrefluxing silicone end-piece. Three months after stenting, the patient complained of sudden discomfort in the bladder area. On the X-ray, the end-pieces of the customized stents seemed to have slipped in the bladder. The customized stents were replaced by new ones after truncating and adjusting their lengths to the exact ureteric length and stent-related symptoms were then improved again. In the field of stent-related symptoms, stent mobility needs more attention than its intravesical position. The case hereby reported illustrates the variations of the symptoms which seem related to the stent mobility, the necessary shaping of the stent and, the possible research avenues for an innovative dynamic ureteric stent.
\end{abstract}

Keywords: ureteral stent, quality of life, urinary symptoms, new approach

\section{Introduction}

Renal obstruction caused by ureteric malignant mass or stenosis is a challenge in the management of malignant diseases. ${ }^{1,2}$ To achieve ureteric patency, doublepigtail stents are frequently implanted in the ureter in urological practice. But, this stent is poorly tolerated, severely impairing the quality of life of patients. ${ }^{3}$ Moreover, indwelling stent-related symptoms induce additional suffering to the preexisting bladder disease. Finally, obstruction may induce renal failure, and chronic renal insufficiency is a barrier to several therapies. ${ }^{4}$

Double-pigtail stent has been widely used in urology for half a century now, ${ }^{5}$ but this device reduces the patient's quality of life. Current stent designs and materials are limited and novel concepts to treat and prevent stent-related symptoms are greatly required. ${ }^{3}$

The perfect ureteric stent should demonstrate optimal patency and should be well tolerated by the patient. ${ }^{6}$ By decreasing the amount of material within the bladder, it should be possible to attenuate the symptoms linked to the stent. ${ }^{7-9}$ To keep an 


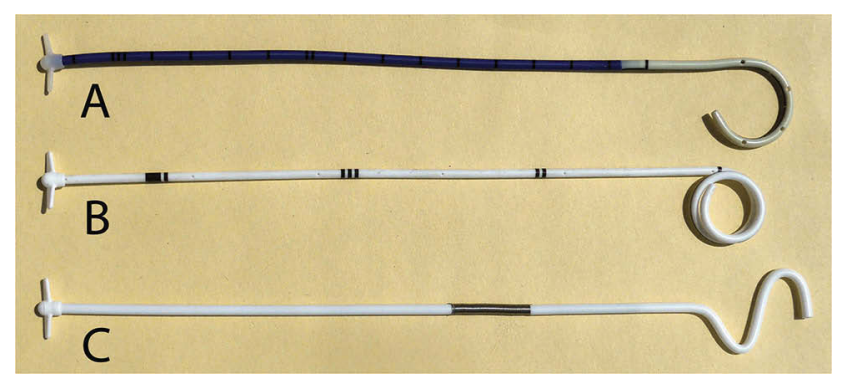

Figure I (A) The major characteristic of the current customized stent was in the replacement of the bladder part of the double-pigtail stent by a nonrefluxing silicone end-piece. (B) Theoretical embodiment of the customised stent with a multiplicity of coiled-up renal loops. (C) Other theoretical embodiment with a spring producing a dynamic action on the end-piece during breathing movements.

effective ureteric drainage and minimize the amount of material left in the bladder, a customized stent has been developed to test its feasibility and tolerance. ${ }^{2,4,10}$ The major characteristic of this stent was in the replacement of the bladder part of the double-pigtail stent $(8 \mathrm{~F}, 26 \mathrm{~cm}$, Tumor DD Ureter Stent, Teleflex Medical, Ireland) by a nonrefluxing silicone end-piece (Figure 1A). The study design has been approved by French Ethical. This customized procedure has already been performed in 17 patients and the first results are encouraging. ${ }^{10}$ But it seems that customized stent still needs improvement to get closer to the ideal stent aimed at. The case hereby reported illustrates the necessary shaping of the stent and the possible research avenues for an innovative ureteric stent.

\section{Case Presentation}

A 55-year-old patient was treated for colonic cancer with surgery and radiotherapy and is now in remission. Twenty years after treatment, a ureteric stent insertion in the right side was performed for benign ureteric obstruction with renal colic. After recurrent stent obstruction and acute pyelonephritis in less than 4 months, stent replacement was attempted via an alternative option by tandem ureteric stents. This procedure, with two stents in the bladder, allowed to maintain kidney function but impaired the quality of life of the patient.

Several questionnaires have been developed to identify ureteric stent-related symptoms. The Ureteral Stent Symptom Questionnaire (USSQ) is widely used to explore stent-related symptoms in six domains, including urinary symptoms. ${ }^{11}$ Regarding the USSQ subscores for urinary symptoms, the patient with two double-pigtail stents had a score of 37 while a non-stented patient has usually a score of $15 .{ }^{11}$ The replacement of the bladder-loops by two silicone end-pieces, reducing the amount of material in the bladder, decreased the score from 37 to 33 . The decrease in the score may not seem substantial, but yet, it turned out that urinary symptom subscores improved the patient's comfort in terms of urgency, frequency and incontinence.

Three months after stenting with customized stent, for no reason and no infection, the patient had to rush to the toilet to urinate all the time. On the X-ray, the end-pieces of the customized stents were crossing the perpendicular line that goes through the middle of the symphysis pubis (Figure 2). Stent-related symptoms were improved after truncating the customized stent and adjusting its length to the exact ureteric length (Figure 3).

\section{Discussion}

It seems necessary to minimize the amount of material in the bladder in order to decrease bladder mucosal irritation. ${ }^{7-9}$ Stents of several sizes, forms, and compositions have been studied, with the aim of reducing stent-related symptoms.

The influence of the size of the bladder-loop end showed controversial results.

Kawahara et $\mathrm{al}^{12}$ reported that the Polaris Loop ${ }^{\circledR}$ with two soft distal loops significantly reduced almost all of stent-related symptoms, but neither Lingeman nor Davenport nor Park and his collaborators found significant reduction in bladder irritation with the Polaris Loop ${ }^{\circledR}$. $^{7,13,14}$

Nestler et al compared patients with various stent sizes (4.7, 6 or 7F) and concluded that scores of USSQ were in favor of the smaller stent and that a significant difference was found in urinary symptom scores. ${ }^{9}$

Dunn et al showed that the thinned tail (3F) of the Tail Stent produced significantly less irritating symptoms than the standard 7F double-pigtail stent. ${ }^{15}$

Recently, Betchard et al published a review about the stent-related symptoms and the authors concluded that although there is a lack of well-designed trials of adequate power, it seems that stent-related symptoms cannot be influenced by stent diameter. ${ }^{3}$

However, in a previous study, the replacement of the bladder part of the double-pigtail stent by a thin $0.3 \mathrm{~F}$ suture thread significantly decreased urinary symptom scores of USSQ. ${ }^{8}$

The replacement of the bladder-loop by a small endpiece results in the presence of only tiny amounts of material in the bladder.

With silicone end-pieces, the decrease in the score may not seem substantial in the patient. First, the patient probably had an impaired bladder even before stenting. Second, a 

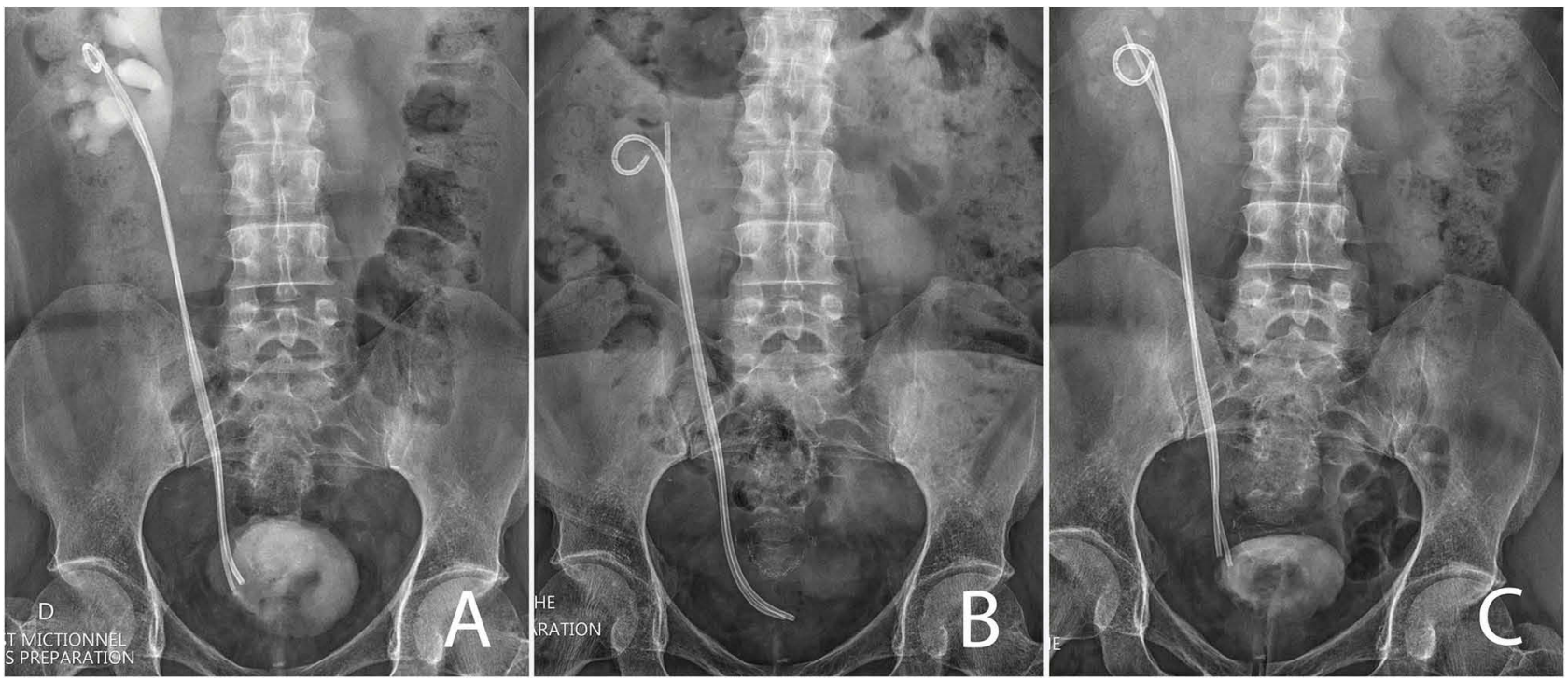

Figure 2 Appearance of customized tandem ureteric stents on X-ray. (A) Improvement of the bladder symptoms by setting the end-pieces on the ureteric orifice. (B) Possible stents dislodgment with recurrence of symptoms. (C) Improvement of the symptoms after adjusting the customized stents.

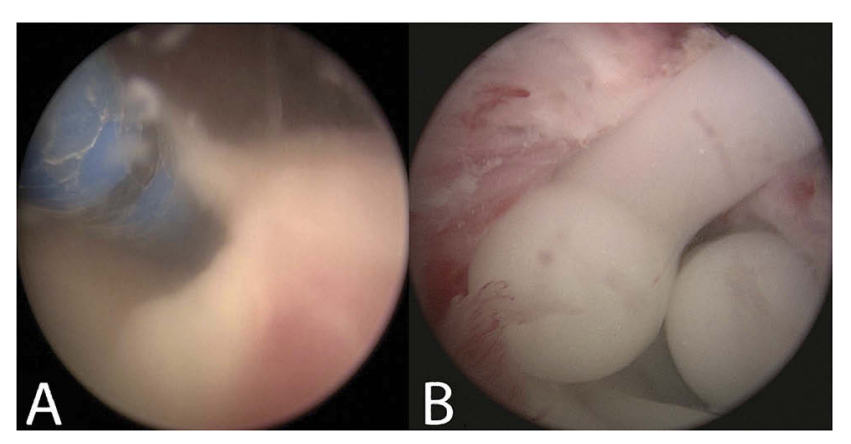

Figure 3 Endoscopic appearance of customized stents. (A) Stents dislodgment in the bladder. (B) Silicone end-pieces in ureteric orifice.

preliminary report concerning four patients seemed to decrease USSQ urinary symptom scores from 36.5 to 25.5 by the replacement of a double-pigtail stent by the new customized stent. For the patient, the replacement of the bladderloops by two silicone end-pieces lowered the score from 37 to 33 only, but yet it turned out that urinary symptom subscores improved the patient's comfort in terms of urgency, frequency and incontinence. Overall, the patient preferred to have the customized stents than two double-pigtail stents.

Tandem stents have been developed as alternatives to single ureteric stents, while maintaining internal drainage. $^{1,4}$ Two bladder loops logically result in the presence of larger amounts of material in the bladder, but in a review on the management of malignant ureteric obstruction, Elsamra et al made no mention of any increase in bladder intolerance with tandem than with a single ureteric stent. ${ }^{1}$
Three months after stenting, the patient complained of sudden discomfort in the bladder area. On the X-ray, the end-pieces of the customized stents seemed to have slipped in the bladder.

The effects of intravesical stent position remain a matter of debate.

A short bladder loop seems to be preferable to a long loop extending throughout the bladder. ${ }^{16}$ But stent position did not significantly influence associated morbidity in several other studies. ${ }^{17,18}$ In addition, Betschart et al showed a high flexibility of the stent location during the indwelling time and called into question the X-ray approach in the assessment of the intravesical stent position. In summary, the authors came to the conclusion that most of the trials showed that the use of shorter stent-ends in the bladder proved more beneficial. ${ }^{3}$

The improvement of the stent-related symptoms by the truncating of the stents suggests that only the end-piece should cross the junction between the ureter and the bladder and float in the bladder itself.

Interestingly, in an evaluation with 13 patients, Zimskind et al observed that the downward dislodgment of the stent has been surprisingly rare and, it appeared that the malignant-obstructed segment of the ureter binds the stent firmly in place. Moreover, another surprising feature has been the lack of bladder irritability on the bladder mucosa. ${ }^{5}$

Maybe the focus should be on stent mobility rather than its intravesical stent position. 
The perfect ureteric stent should demonstrate optimal patency and should be well tolerated by the patient. ${ }^{6}$ The section of the stent to the exact length of the ureter may be an incomplete method because breathing movements seem to induce the snagging of the end-piece into the bladder mucosa.

A permanent retention of the end-piece could be obtained by a spring effect of the renal part of the stent on the end-piece. For this purpose, the use of a multiplicity of coiled-up renal loops as a Multi-length Stent is one possible embodiment (Figure 1B). But ureteric adaptations with indwelling time could lead to the dislodgment of the renal-loops in the lumbar ureter causing the stent to slide again.

Another embodiment using a spring would allow a dynamic adaptation during breathing movements (Figure 1C). This mode has been carried out in vitro and its placement in vivo is technically feasible.

In supplementary material, a short video presented herewith exposes in a model the different stent embodiments of current or theoretical stents and the way they snarl up into the bladder mucosa.

There were several limitations to the present study. First, the study concerns only one patient. Second, it seems that customized stent still needs improvement to get closer to the ideal stent aimed at. Third, the use of a spring is only a theoretical embodiment and needs further studies.

The further areas of research planned for the ideal ureteral stent should focus on the thinning of the intravesical material.

\section{Conclusion}

The concept of material reduction within the bladder seems to be a promising research avenue.

In the field of stent-related symptoms, maybe stent mobility should focus attention more than its intravesical stent position.

With customized stent, by retaining the end-piece on the ureteric orifice, it should be possible to alleviate permanently the bladder symptoms.

New concepts and new shapes exist, probably improving the patient's comfort, and further studies are greatly required.

\section{Ethics Statement}

All procedures performed in studies involving human participants were in accordance with the ethical standards of the institutional and/or national research committee (French Ethical Committee (CPP 17-VOGT-01), National
Medicine Safety Agency (2017-A00205-48)) and with the 1964 Helsinki declaration and its later amendments or comparable ethical standards.

\section{Informed Consent}

Written informed consent for the case details and accompanying images published was obtained from the patient included in the study.

\section{Acknowledgments}

I thank Professor Janine Dove-Rumé, English Department at the University of Tours, for re-reading the text.

\section{Disclosure}

Benoît Vogt is a consultant for Rocamed outside of the submitted work. The author reports no other conflicts of interest in this work.

\section{References}

1. Elsamra SE, Leavitt DA, Motato HA, et al. Stenting for malignant ureteral obstruction: tandem, metal or metal-mesh stents. Int J Urol. 2015;22(7):629-636. doi:10.1111/iju.12795

2. Vogt B, Desfemmes FN, Desgrippes A. Improving comfort of patients with ureteral obstruction and malignant disease should be of concern. $J$ Palliat Med. 2016;19(11):1132-1133. doi:10.1089/jpm.2016.0276

3. Betschart P, Zumstein V, Piller A, Schmid HP, Abt D. Prevention and treatment of symptoms associated with indwelling ureteral stents: a systematic review. Int J Urol. 2017;24(4):250-259. doi:10.1111/iju.13311

4. Vogt B. Ureteral stent obstruction and stent's discomfort are not irreparable damages. Urol Case Rep. 2018;29(20):100-101. doi:10.1016/j. eucr.2018.07.025

5. Zimskind PD, Fetter TR, Wilkerson JL. Clinical use of long-term indwelling silicone rubber ureteral splints inserted cystoscopically. $J$ Urol. 1967;97(5):840-844. doi:10.1016/s0022-5347(17)63130-6

6. Al-Aown A, Kyriazis I, Kallidonis P, et al. Ureteral stents: new ideas, new designs. Ther Adv Urol. 2010;2(2):85-92. doi:10.1177/1756287210 370699

7. Lingeman JE, Preminger GM, Goldfischer ER, Krambeck AE. Assessing the impact of ureteral stent design on patient comfort. $J$ Urol. 2009;181(6):2581-2587. doi:10.1016/j.juro.2009.02.019

8. Vogt B, Desgrippes A, Desfemmes FN. Changing the double-pigtail stent by a new suture stent to improve patient's quality of life: a prospective study. World J Urol. 2015;33(8):1061-1068. doi:10.1007/ s00345-014-1394-2

9. Nestler S, Witte B, Schilchegger L, Jones J. Size does matter: ureteral stents with a smaller diameter show advantages regarding urinary symptoms, pain levels and general health. World J Urol. 2019. doi:10.1007/s00345-019-02829-0

10. Vogt B. A new ureteric stent with silicone end piece to improve patient's comfort (UP6-47). J Endourol. 2018;32(S2):A489-A490. doi:10.1089/end.2018.29043.abstracts

11. Joshi HB, Newns N, Stainthorpe A, MacDonagh RP, Keeley FX Jr, Timoney AG. Ureteral stent symptom questionnaire: development and validation of a multidimensional quality of life measure. $J$ Urol. 2003;169(3):1060-1064. doi:10.1097/01.ju.0000049198.53424.1d

12. Kawahara T, Ito H, Terao H, et al. Changing to a loop-type ureteral stent decreases patients' stent-related symptoms. Urol Res. 2012;40 (6):763-767. doi:10.1007/s00240-012-0500-4 
13. Davenport K, Kumar V, Collins J, Melotti R, Timoney AG, Keeley FX Jr. New ureteral stent design does not improve patient quality of life: a randomized, controlled trial. J Urol. 2011;185(1):175-178. doi:10.1016/j.juro.2010.08.089

14. Park HK, Paick SH, Kim HG, Lho YS, Bae S. The impact of ureteral stent type on patient symptoms as determined by the ureteral stent symptom questionnaire: a prospective, randomized, controlled study. J Endourol. 2015;29(3):367-371. doi:10.1089/end.2014.0294

15. Dunn MD, Portis AJ, Kahn SA, et al. Clinical effectiveness of new stent design: randomized single-blind comparison of tail and double-pigtail stents. $J$ Endourol. 2000;14(2):195-202. doi:10.1089/end.2000.14.195
16. Giannarini G, Keeley FX Jr, Valent F, et al. Predictors of morbidity in patients with indwelling ureteric stents: results of a prospective study using the validated ureteric stent symptoms questionnaire. BJU Int. 2011;107(4):648-654. doi:10.1111/j.1464-410X.2010.09482.x

17. Abt D, Mordasini L, Warzinek E, et al. Is intravesical stent position a predictor of associated morbidity? Korean J Urol. 2015;56(5):370378. doi:10.4111/kju.2015.56.5.370

18. Calvert RC, Wong KY, Chitale SV, et al. Multi-length or $24 \mathrm{~cm}$ ureteric stent? A multicentre randomised comparison of stentrelated symptoms using a validated questionnaire. BJU Int. 2013;111(7):1099-1104. doi:10.1111/j.1464-410X.2012.11388.x

\section{Publish your work in this journal}

Research and Reports in Urology is an international, peer-reviewed, open access journal publishing original research, reports, editorials, reviews and commentaries on all aspects of adult and pediatric urology in the clinic and laboratory including the following topics: Pathology, pathophysiology of urological disease; Investigation and treatment of urological disease; Pharmacology of drugs used for the treatment of urological disease. The manuscript management system is completely online and includes a very quick and fair peer-review system, which is all easy to use. Visit http://www.dovepress.com/ testimonials.php to read real quotes from published authors. 